J. Dairy Sci. 95:2397-2408

http://dx.doi.org/10.3168/jds.2011-4535

(C) American Dairy Science Association ${ }^{\circledR}, 2012$.

\title{
Supplemental feeding with glycerol or propylene glycol of dairy cows in early lactation-Effects on metabolic status, body condition, and milk yield
}

\author{
H. Lomander, ${ }^{\star 1}$ J. Frössling, ${ }^{*}$ K. L. Ingvartsen, † H. Gustafsson,‡ and C. Svensson§ \\ *Department of Animal Environment and Health, Swedish University of Agricultural Sciences, PO Box 234, SE-532 23 Skara, Sweden \\ †Department of Animal Science, Aarhus University, PO Box 50, DK-8830 Tjele, Denmark \\ $\ddagger$ Swedish Dairy Association and Department of Clinical Sciences, Swedish University of Agricultural Sciences, PO Box 7054, \\ SE-750 07 Uppsala, Sweden \\ §Växa Sverige, Regional Dairy Association, PO Box 814, SE-391 28 Kalmar, Sweden
}

\begin{abstract}
The objective of this field study was to evaluate the effect of supplemental feeding with glycerol or propylene glycol to dairy cows in early lactation on metabolic status, body condition and milk yield. In total, 673 newly calved cows from 12 commercial Swedish dairy herds were randomized to daily supplementation with $450 \mathrm{~g}$ of glycerol (GLY), $300 \mathrm{~g}$ of propylene glycol (PG), or nothing (control, CON). Supplements were fed twice daily from 0 to $21 \mathrm{~d}$ in milk (DIM) as a top dress on concentrates. For each cow, data on parity, breed, calving date, monthly test-day milk yield, and cases of diseases were collected. Blood samples were taken at approximately 2,5 , and 8 wk postpartum (pp) and analyzed for glucose, $\beta$-hydroxybutyrate (BHBA), nonesterified fatty acids (NEFA), and insulin. Samples taken within $3 \mathrm{wk}$ pp were also analyzed for insulin-like growth factor 1 (IGF-1). Measurements of body condition score (BCS) and heart girth (HG) were obtained at approximately 2 and $5 \mathrm{wk}$ pp and at time of first insemination. The effects of supplemental feeding with GLY or PG on the plasma concentrations of glucose, NEFA, BHBA, insulin, and IGF-1, and BCS, HG, and occurrence of disease were analyzed. No differences in BCS or HG or in plasma concentrations of glucose, BHBA, NEFA, or IGF-1 were found between the control group and any of the treatment groups. Cows in the GLY group had lower plasma insulin concentrations during DIM 0 to 63 compared with group CON, but no difference in insulin was found between the PG group and the CON group. Cows supplemented with GLY had a higher milk yield ( $\mathrm{kg}$ of milk and $\mathrm{kg}$ of energycorrected milk) during the first 90 DIM. Cows in the PG group tended to yield more milk during the same period. No differences in the occurrence of diseases were
\end{abstract}

Received May 16, 2011.

Accepted December 29, 2011.

${ }^{1}$ Corresponding author: Hanna.Lomander@slu.se seen between the groups. In conclusion, supplementation with GLY in early lactation did increase milk yield without a subsequent decrease of metabolic status, and supplementation with PG tended to do the same.

Key words: negative energy balance, randomized field study, ketosis, variance decomposition

\section{INTRODUCTION}

During the transition period, the dairy cow experiences a dramatically increased demand for nutrients for the growing fetus and the initiation of lactation. To increase and maintain lactation, homeorhetic regulation supports adaptation and changes nutrient partitioning. The changed nutrient partitioning involves decreased lipogenesis and increased lipolysis, and results in a state of negative energy balance (NEB) and a depressed DMI in spite of the increased nutrient needs (Ingvartsen and Andersen, 2000). The shift in the rate of lipogenesis and lipolysis causes increased concentration of NEFA in the blood. The NEFA could be completely oxidized to carbon dioxide, partly oxidized to ketone bodies (e.g., BHBA) or be stored in the liver as triglycerides. In turn, ketone bodies may be used by muscles as an alternative source of energy to spare glucose for milk production. When the plasma concentration of NEFA is high, the oxidative capacity of the liver may be exceeded, which leads to an increase of BHBA in plasma (Drackley et al., 2005; Ingvartsen, 2006).

Although mobilization of body fat tissue is a physiological adaptation in the high-yielding dairy cow in $\mathrm{NEB}$, this can have a negative effect on health and productivity. In early lactation, cows with metabolic profiles indicating a severe NEB; for example, high concentrations of NEFA, have an increased risk of diseases such as clinical ketosis, displaced abomasum, metritis, or retained placenta (Ingvartsen, 2006; Ospina et al., 2010a). Increased concentrations of BHBA and NEFA in cows after calving are also associated with decreased 
milk production (Ospina et al., 2010b) and increased risk of mastitis (Suriyasathaporn et al., 2000). A severe NEB could also decrease the fertility of the cow (Friggens, 2003; Ingvartsen 2006; Ospina et al., 2010b).

Glycerol (GLY) and propylene glycol (PG) have long been used as treatment or prophylaxis against ketosis (Johnson, 1954; Fisher et al., 1973). After ingestion, GLY is mainly fermented to VFA by rumen microbes (Rémond et al., 1993), absorbed and entered in the glucogenic pathway. However, VFA pattern results are inconsistent between studies (Donkin and Doane, 2007). Propylene glycol provides substrates for gluconeogenesis and induces insulin resistance in peripheral tissues to spare glucose for the udder (Kristensen and Raun, 2007). Experimental studies have shown that an oral drench of GLY or PG can be effective in increasing glucose and decreasing NEFA and BHBA (Goff and Horst, 2001; Linke et al., 2004; Nielsen and Ingvartsen, 2004; Osman et al., 2008; Rizos et al., 2008). However, drenching all newly calved cows on a routine basis is labor intensive and could be questionable from an animal welfare perspective. The effects of GLY and PG when they are fed mixed or top dressed in concentrates or a TMR have been investigated, but most of these studies were carried out on experimental stations and on a limited number of animals. Previous studies on the effect of GLY on milk yield are contradictory and, to our knowledge, no studies have found a significant positive effect of PG on milk yield. Nevertheless, products based on these substances are often claimed to increase milk production.

The aim of the present study was to investigate, under practical farm conditions, whether supplemental feeding with PG or GLY during the first 21 DIM affects the metabolic status, BCS, heart girth (HG) measurement, or milk yield in Swedish dairy cows.

\section{MATERIALS AND METHODS}

\section{Herds and Animals}

The study was performed in 12 commercial dairy herds in southwest Sweden from October 1, 2007, until February 28, 2009. Conventional herds located in the vicinity of the Swedish University of Agricultural Sciences in Skara that were affiliated with the Swedish official milk recording scheme (SOMRS) and had tiestalls and more than 45 calving cows per year $(\mathrm{n}=138)$ were asked to participate in the study. Twelve farmers volunteered to participate. These 12 herds had, on average, 60 cows (range 45-105), were milked twice daily, and produced between 9,100 and 11,500 $\mathrm{kg}$ of ECM per cow and year $(365 \mathrm{~d})$. An individual diet of grass silage and concentrate, according to the monthly milk production and BCS of the cow (National Research Council, 2001), was fed in all herds. On 5 farms, grass hay (1 kg per cow and day) was fed as a complement. During summer, the cows in all herds were on pasture (cultivated pasture or semi-natural grassland) for at least $6 \mathrm{~h} / \mathrm{d}$ for $3 \mathrm{mo}$. The breeds represented in this study were Swedish Holstein (SH), Swedish Red cattle (SR), and cross breed or other breed (other). The distribution of breeds among herds differed and no herd had only one breed. Detailed information on number of animals in each treatment group, farm, breed, parity, and calving season is presented in Table 1.

Table 1. Number of cows per treatment group, breed, parity, calving season, and herd, respectively, fed supplements with glycerol (GLY), propylene glycol (PG), or nothing (controls, CON) in early lactation in a Swedish field study (2007-2009)

\begin{tabular}{|c|c|c|c|c|c|c|c|c|c|c|c|}
\hline \multirow[b]{2}{*}{ Farm } & \multicolumn{3}{|c|}{ Treatment } & \multicolumn{3}{|c|}{ Breed $^{1}$} & \multicolumn{3}{|c|}{ Parity } & \multicolumn{2}{|c|}{ Calving season ${ }^{2}$} \\
\hline & GLY & $\mathrm{PG}$ & $\mathrm{CON}$ & $\mathrm{SR}$ & $\mathrm{SH}$ & Other & 1 & 2 & $\geq 3$ & Summer & Winter \\
\hline $\mathrm{C}$ & 17 & 16 & 17 & 7 & 40 & 3 & 14 & 14 & 22 & 27 & 23 \\
\hline $\mathrm{D}$ & 26 & 25 & 25 & 11 & 26 & 39 & 35 & 20 & 21 & 8 & 68 \\
\hline $\mathrm{E}$ & 20 & 19 & 20 & 10 & 40 & 9 & 26 & 12 & 21 & 20 & 39 \\
\hline $\mathrm{H}$ & 23 & 24 & 25 & 69 & 0 & 1 & 28 & 13 & 29 & 37 & 33 \\
\hline I & 15 & 15 & 17 & 41 & 6 & 0 & 18 & 12 & 17 & 19 & 28 \\
\hline $\mathrm{J}$ & 14 & 14 & 14 & 41 & 1 & 0 & 16 & 15 & 11 & 27 & 15 \\
\hline $\mathrm{K}$ & 20 & 22 & 21 & 19 & 34 & 10 & 24 & 18 & 21 & 30 & 33 \\
\hline $\mathrm{L}$ & 15 & 15 & 16 & 44 & 1 & 1 & 12 & 17 & 17 & 25 & 21 \\
\hline Total no. of cows & 224 & 222 & 227 & 336 & 214 & 85 & 243 & 190 & 240 & 297 & 388 \\
\hline
\end{tabular}

${ }^{1} \mathrm{SR}=$ Swedish Red; $\mathrm{SH}=$ Swedish Holstein; Other = crossbreed or other breed

${ }^{2}$ Summer $=$ cows calving between April 1 and September 30; winter = cows calving between October 1 and March 31. 


\section{Study Design and Collection of Data}

At calving, the individual cows $(\mathrm{n}=673)$ within each herd were randomized to 1 of 3 treatment groups: refined glycerol (purity 99.5\%, GLY), propylene glycol (PG), or control (CON; Table 1). For the first 21 DIM, cows in the GLY group received $450 \mathrm{~g}$ of liquid GLY daily, whereas those in the PG group received $300 \mathrm{~g}$ of liquid PG daily. The supplements were poured on top of the concentrate twice daily. The CON group received no supplement. The cows were not grouped in the barns according to supplemental group. Before distribution to the farms, the GLY and PG were diluted with water to make doses correspond to equal volumes. The supplements, which were colorless, odorless, and viscous, were delivered to the farms in color-coded bottles to blind the farmers to treatment. The intended doses of GLY and PG used in this study were calculated based on amount of carbon equivalents, where $300 \mathrm{~g}$ of PG corresponded to $450 \mathrm{~g}$ of crude GLY. However, due to a mistake discovered after the study was conducted, a dose of $450 \mathrm{~g}$ of refined GLY was used instead of crude GLY, and thus the doses were not equivalent.

During the study period, the farms were visited every third week at approximately the same time of day for collection of blood samples. The focus of the sampling protocol chosen was to detect any long-term effects, rather than immediate effects, on the metabolic status following supplemental feeding. From each cow, 3 blood samples were taken at 3 -wk intervals within 5 to 63 DIM [i.e., 1 to 3,4 to 6 , and 7 to 9 wk postpartum (pp)] via puncture of the coccygeal vein or artery, using a vacuum tube coated with Na-heparin (BD Vacutainer, Plymouth, UK). Tubes were immediately placed on ice and centrifuged at 2,000 $\times g$ for 20 min within $1 \mathrm{~h}$ after sampling. The plasma was transferred to plastic tubes and kept on ice during transport from the farm. It was then stored at $-18^{\circ} \mathrm{C}$ until analysis. Furthermore, the BCS of cows in the treatment groups was assessed according to Edmonson and coworkers (1989) and HG was measured. For each individual cow, BCS and HG were measured on 3 occasions; at first visit after calving (1 to $3 \mathrm{wk} \mathrm{pp),} \mathrm{at} 4$ to $6 \mathrm{wk} \mathrm{pp}$, and at the time of first insemination (if $<63$ DIM). Body condition scoring was made by the same veterinarian (the corresponding author) throughout the study, except for 3 wk during summer 2008 when farm visits were carried out by another veterinarian. The veterinarians were trained together to obtain similar scoring.

Records of each cow's treatment group, calving date, and cases of diseases not treated by a veterinarian were kept by the farmers using standardized protocols. Cases of diseases treated and reported by a veterinarian were obtained from the Swedish national disease recording system (Olsson et al., 2001). Information about breed, parity, and monthly milk yield $(\mathrm{kg})$ and milk composition ( $\mathrm{kg}$ of fat and protein) were collected from SOMRS. Milk data from the monthly test-days within 90 DIM were used, except for the first 5 DIM. Yield of ECM $(\mathrm{kg})$ was calculated using the formula $0.25 \times \mathrm{kg}$ of milk $+12.2 \times \mathrm{kg}$ of fat $+7.7 \times \mathrm{kg}$ of protein (Swedish Dairy Association, 2004).

Sixteen cows were lost to follow up because the farmer decided to stop the supplemental feeding of these animals before 21 DIM, due to severe illness $(n=6)$, death $(\mathrm{n}=4)$, severely decreased appetite $(\mathrm{n}=4)$, or unknown reason $(\mathrm{n}=2)$. Of these cows, 9 were from the GLY group and 7 from the PG group. One herd left the study halfway through the study period because of personnel reasons (herd D; see Table 1). Cows from this herd were included in the statistical analyses if they had completed $21 \mathrm{~d}$ of supplemental feeding.

The use of animals as research objects in this study was approved by the regional animal ethics committee, Gothenburg, Sweden.

\section{Laboratory Investigations}

Plasma samples showing evident hemolysis $(\mathrm{n}=$ 33) were excluded from the study. Remaining samples $(1,779$ in total) were analyzed for glucose, NEFA, BHBA, and insulin. Samples taken from 0 to 23 DIM (n $=547$ ) were also analyzed for IGF-1. All analyses were performed at the laboratory of Department of Animal Health and Bioscience, Aarhus University (Foulum, Denmark).

The analyses of blood metabolites (i.e., glucose, NEFA, and BHBA) were performed by using an auto analyzer (ADVIA 1650 Chemistry System, Siemens Medical Solutions, Tarrytown, NY). Intraassay precision was $<2 \%(\mathrm{CV})$ and interassay precision was $<3 \%$ (CV) for all 3 parameters. Glucose was determined according to a standard enzymatic and colorimetric method (Siemens Diagnostics Clinical Methods for ADVIA 1650). Concentration of NEFA was determined using the Wako NEFA C ACS-ACOD (Wako Chemicals GmbH, Neuss, Germany) assay method, and that of BHBA was determined as an increase in absorbance at $340 \mathrm{~nm}$ due to the production of NADH at slightly alkaline $\mathrm{pH}$ in the presence of $\beta$-hydroxybutyrate dehydrogenase. The method involved oxamic acid in the medium to inhibit lactate dehydrogenase, as proposed by Harano et al. (1985).

Insulin and IGF-1 were determined using noncompetitive time-resolved immunofluorometric assays as described by Løvendahl and Purup (2002). The timeresolved fluorescence from europium was read following chelation with an enhanced solution (Wallac $\mathrm{Oy}$, 
Turku, Finland). For insulin, intra- and interassay CV were $<4.9 \%$ and $<5.1 \%$, respectively ( $\mathrm{n}=14$ assays, $\mathrm{n}=3$ controls; $12.0,51.7$, and $220 \mathrm{pmol} / \mathrm{L})$. For IGF1 , intra- and interassay CV were $<9.0 \%$ and $<5.1 \%$, respectively $(\mathrm{n}=9$ assays, $\mathrm{n}=2$ controls; 110 and 295 $\mathrm{ng} / \mathrm{mL})$.

\section{Statistical Analyses}

Statistical modeling was performed using Stata (release 11, StataCorp LP, College Station, TX). Effects of supplemental feeding with GLY or PG on plasma concentrations of glucose, NEFA, BHBA, and insulin and on BCS, HG, and milk yield (measured as kg of liquid milk or $\mathrm{kg}$ of ECM) were investigated using random intercept regression models for repeated measurements data (Rabe-Hesketh and Skrondal, 2005). Comparisons were made using group CON as baseline, which means that comparisons were made between GLY and CON or between PG and CON, respectively. Categorical variables included in the initial full models as fixed effects were treatment group (GLY, PG, CON), breed (SR, $\mathrm{SH}$, or cross breed/other), parity $(1,2$, or $\geq 3)$, and calving season (April through September or October through March). Day of sampling in relation to calving was included as the continuous variable DIM. Farm was included as a random effect in all models. Cow was included as a random effect in all models except in the IGF-1 model, because IGF-1 was measured only once per cow. The role of milk yield as an explanatory variable was investigated, but was finally left out from the full model. The initial full models were defined by the equation

$$
\begin{gathered}
Y_{i j k}=\beta_{0}+\beta_{D} D_{I M_{i j k}}+\beta_{G 1} \operatorname{GROUP}_{i k}^{1}+\beta_{G 2} \operatorname{GROUP}_{i k}^{2} \\
+\beta_{P 1} \text { PAR }_{i k}^{1}+\beta_{P 2} \text { PAR }_{i k}^{2}+\beta_{B 1} \text { BREED }_{i k}^{1} \\
+\beta_{B 2} \text { BREED }_{i k}^{2}+\beta_{S 1} \text { SEASON }_{i k}+\mu_{k}+\mu_{i k}+e_{i j k},
\end{gathered}
$$

where $Y_{i j k}=$ the response of cow $i\left(i=1, \ldots, N_{k}\right)$ at occasion $j(j=1, \ldots, T)$ in herd $k(k=1, \ldots, K) ; \beta$ terms $=$ the intercept $\left(\beta_{0}\right)$ and regression coefficients expressing included fixed effects; $D I M_{i j k}=$ time of sampling after calving; $G R O U P_{i k}=$ an indicator for treatment group; $P A R_{i k}=$ an indicator for parity; $B R E E D_{i k}=$ an indicator for breed; $S E A S O N_{i k}=$ an indicator for calving season; $\mu_{k}=$ the random intercept for herd $k ; \mu_{i k}$ $=$ the random intercept for cow $i$ in herd $k$; and $e_{i j k}=$ the idiosyncratic error term. The superscripts indicate that a dummy variable was formed from an indicator variable.

Effect of GLY or PG supplementation on plasma concentration of IGF-1 was analyzed using mixed linear
Table 2. The number of observations and cows included in 9 statistical models of the effect of glycerol or propylene glycol supplements in early lactation in 673 dairy cows in 12 Swedish herds (2007-2009)

\begin{tabular}{lcc}
\hline Outcome & Observations & Cows \\
\hline Glucose $^{1}$ & 1,726 & 672 \\
BHBA $^{1}$ & 1,726 & 672 \\
NEFA $^{1}$ & 1,725 & 672 \\
Insulin $^{1}$ & 1,724 & 672 \\
Insulin-like growth factor $^{1}{ }^{1}$ & 547 & 547 \\
BCS & 1,329 & 667 \\
Heart girth & 1,359 & 666 \\
Milk yield & 1,820 & 673 \\
Milk yield ECM & 1,820 & 673 \\
\hline
\end{tabular}

${ }^{1}$ Plasma concentrations.

regression. The initial full model was defined by the equation

$$
\begin{aligned}
Y_{i k} & =\beta_{0}+\mu_{k}+\beta_{G 1} \operatorname{GROUP}_{i k}^{1}+\beta_{G 2} \text { GROUP }^{2}{ }_{i k} \\
+ & \beta_{P 1} P A R_{i k}^{1}+\beta_{P 2} P A R_{i k}^{2}+\beta_{B 1} \text { BREED }_{i k}^{1} \\
& +\beta_{B 2} \text { BREED }_{i k}^{2}+\beta_{S 1} S E A S O N_{i k}^{1}+e_{i k},
\end{aligned}
$$

where $Y_{i k}=$ the response in cow $i\left(i=1, \ldots, N_{k}\right)$ in herd $k(k=1, \ldots, K) ; \beta$ terms $=$ the intercept $\left(\beta_{0}\right)$ and regression coefficients expressing included fixed effects; $G_{R O U P}, P A R_{i k}, B R E E D_{i k}$, and $S E A S O N_{i k}=$ indicator variables as described above; $\mu_{k}=$ the random intercept of farm $k$; and $e_{i k}=$ the idiosyncratic error term.

The number of observations and number of cows included in each model are shown in Table 2. Plasma concentrations of NEFA, BHBA, insulin, and IGF-1 were transformed using the natural logarithm to better reach a normal distribution.

All models were built using backward stepwise elimination. Covariates with a Wald value $\geq 0.1$ were excluded from the preliminary models. However, treatment group was kept in all models. When the reduced models were found for glucose, NEFA, insulin, BCS, HG, and milk yield, the relationship between all outcomes and the continuous predictors, adjusted for other significant covariates, were investigated using a test for first-degree fractional polynomials. Based on the test for best fit and on visual inspection of plots, a polynomial of DIM was used in milk yield models. Interactions between group and DIM, breed, parity, and calving season were investigated. However, no interactions were included in the final models due to highly nonsignificant results or lack of biological relevance.

The fit of the models was assessed by visual inspection of plots of the standardized residuals against the predicted value at cow level and of normal probability plots in which residuals at cow level were plotted against the quartiles. Outliers were detected by visual 
inspection of plots of leverage, obtained from regression models against normalized squared residuals. The fit of the final models were considered satisfactory. Values of metabolites and insulin were predicted based on the final models and plotted against DIM to obtain graphs of differences between treatment groups.

The sources of variation in the final models regarding metabolites, insulin, IGF-1, BCS, HG, and milk yield were evaluated. The proportions of variance explained by the random effects in the final models, corresponding to the hierarchical structure of the data (i.e., farm, cow, and residual) were calculated by comparing the final models with a model containing only a constant.

Diseases were defined in 4 categories: ketosis (ketosis, feed depression or displacement of the abomasum), mastitis (acute mastitis or fever caused by other infection), paresis (puerperal paresis or hypomagnesemia), or other disease. Differences in occurrence of the disease categories during 0 to 90 DIM, as reported by the farmer or a veterinarian, were tested by comparing the number of cases and noncases (excluding cases of recurrence) in the CON group with the corresponding numbers in the GLY or PG group, respectively (Fisher's exact test). Tests were carried out separately for the different categories of diseases. Cows that were excluded from the period of supplemental feeding were not included in these analyses.

\section{RESULTS}

We observed a marked increase in plasma concentration of glucose $(P<0.0001)$ in all treatment groups during the first 9 wk in lactation (Figure 1A), whereas NEFA decreased $(P<0.0001)$ in all 3 groups during the same period (Figure 1B). No differences were found between $\mathrm{CON}$ and either of the treatment groups in glucose $(P=0.47)$ or NEFA $(P=0.47)$. Within cow, BHBA did not change over time $(P=0.48$, Figure $1 \mathrm{C})$ and no differences $(P=0.33)$ were seen between any of the treatment groups and the control group. However, insulin, which in general increased over time $(P<$ 0.0001, Figure 1C), had lower values in the GLY group (compared with CON, $P=0.01$ ), whereas cows in the PG group did not differ $(P=0.13)$ compared with CON (Figure 1D). Finally, no differences were seen in IGF-1 between the GLY or PG group and the CON group $(P=0.32)$. Estimated effects from models of glucose, NEFA, BHBA, insulin, and IGF-1 are compiled in Tables 3 and 4 .

Body condition score across treatment groups and adjusted for other covariates were $2.9 \pm 0.04$ during the first $3 \mathrm{wk}$ pp and $2.5 \pm 0.04$ during wk 7 to $9 \mathrm{pp}$. Corresponding measurements of HG across groups were $198 \pm 0.41 \mathrm{~cm}$ during the first $3 \mathrm{wk}$ pp and $194 \pm 0.45$ cm during wk 7 to $9 \mathrm{pp}$. Body condition score $(P=$ $0.78)$ and HG $(P=0.87)$ did not differ between the cows in group CON and either of the treatment groups.

Milk yield, measured as the mean milk yield in kilograms at monthly test-days during the first 90 DIM, was $37.2 \pm 0.32$ in GLY, $36.7 \pm 0.34$ in $\mathrm{PG}$, and 32.6 \pm 0.36 in CON. As indicated in Figure 2A, milk yield increased in all treatment groups during the first 40 DIM, followed by a plateau phase at the end of the study period $(P<0.0001)$. For this outcome, treatment group was significant $(P=0.03)$ and cows in the GLY group produced $1.24 \mathrm{~kg}(95 \% \mathrm{CI}=0.28-2.20)$ more milk per day compared with cows in CON. A tendency $(P=0.06)$ was observed for cows in the PG group to have a higher daily milk yield compared with $\mathrm{CON}$ cows $(0.94 \mathrm{~kg}, 95 \% \mathrm{CI}=-0.03-1.91)$

Yield of ECM followed the same pattern as milk yield and tended to differ between the groups $(P=0.10$, Figure 2B). Cows in the GLY group produced $0.95 \mathrm{~kg}$ more ECM $(95 \%$ CI $=0.03-1.86, P=0.04)$ per day during the first 90 DIM compared with cows in CON. No differences were seen between the PG group and the CON group $(P=0.11)$. Estimated effects from random coefficient models of milk yield are shown in Table 5 .

The proportions of variance at each level of hierarchy in the models of the different outcomes are presented in Table 6. Overall, the variation in all models was lowest at the level of herd and highest at the levels of cow and residual. For hormones and metabolites, between 47 and $59 \%$ of the variation was unexplained error. Of the remaining random variation, explained variation at the cow level was in general more than twice the variation explained at the herd level.

Definitions of disease diagnoses and descriptive statistics of disease occurrence from 0 to 90 DIM in the cows that fulfilled the period of supplemental feeding is presented in Table 7 . No observations were further excluded from the statistical modeling due to disease. Of all cows in the GLY, PG, and CON groups, 50, 48 , and 53 cows, respectively, were diagnosed with one or more of the defined diseases on one or more occasions between 0 and 90 DIM. However, no significant differences were found between control cows and cows treated with GLY $(0.58<P<1)$ or PG $(0.21<P<$ $0.59)$ for any of the diagnoses.

\section{DISCUSSION}

In this field study with 673 dairy cows from 12 commercial herds, cows supplemented with GLY in early lactation had increased milk yield (both $\mathrm{kg}$ of milk and $\mathrm{kg}$ of ECM) during the first $3 \mathrm{mo}$ of lactation, compared with cows in the control group. Previous studies of supplementation with GLY in early lactation have 

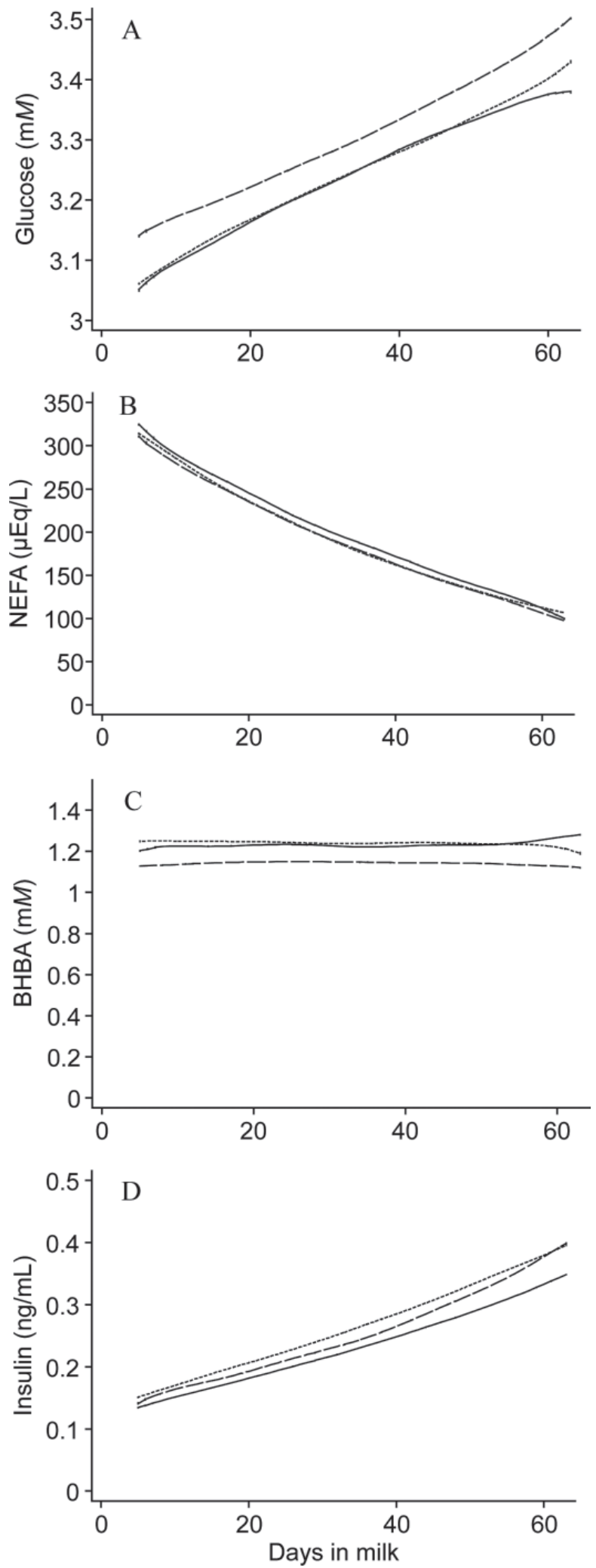

Figure 1. Predicted plasma concentrations of (A) glucose, (B) NEFA, (C) BHBA, and (D) insulin across 672 dairy cows receiving supplemental feeding with glycerol $(-)$, propylene glycol $(---)$, or control (...) from 0 to 21 DIM. found unaffected milk yield (Wang et al., 2009) or a tendency toward lower milk yield (DeFrain et al., 2004) compared with unsupplemented controls. On the other hand, Bodarski and coworkers (2005) reported that cows supplemented with GLY in a TMR had a higher daily milk yield during the first 10 wk of lactation compared with controls. Several studies report increased glucose levels during treatment with glycerol (DeFrain et al., 2004; Osman et al., 2008; Wang et al., 2009). Because of the homeostatic regulation of glucose, its value as an indicator of metabolic status is questionable, whereas NEFA and BHBA are considered more reliable as indicators (Ingvartsen et al., 2003; LeBlanc, 2010). In present study, the increased milk yield without a subsequent increase in NEFA and BHBA might indicate that the metabolic status of cows was improved due to supplementation with GLY.

Cows supplemented with PG in early lactation tended to have a higher yield of milk compared with control cows. This difference in milk yield was not found in analyses of ECM, which might indicate that PG induced a deprivation of milk protein or fat, as previously reported by Liu et al. (2009). Our result is in accordance with other studies, where milk yield in cows supplemented with PG in early lactation was unchanged or showed a tendency toward an increase (Hoedemaker et al., 2004; Juchem et al., 2004; Chung et al., 2009a). In addition, we did not find any improvements in the metabolic status of cows supplemented with PG. As reviewed by Nielsen and Ingvartsen (2004), supplementation with $\mathrm{PG}$ generally increases glucose and insulin and decreases BHBA and NEFA. However, Chibisa and coworkers (2008) found that when PG was fed in a higher dose and for a longer period $(600 \mathrm{~mL}$ daily for 7 d prepartum until 45 DIM) than in the present study, NEFA, BHBA, and insulin remained unaffected.

When comparing different studies regarding effects of GLY and PG, several factors need to be consideredmethod of administration, time of sampling in relation to time of administration or time of calving, dose, and physiologic status of the animal (Nielsen and Ingvartsen, 2004). The effect of GLY or PG seems to be dependent upon rapid delivery, as indicated in studies comparing either of the substances given as oral drenches or mixed with concentrates or in a TMR (Christensen et al., 1997; Linke et al., 2004; Chung et al., 2009b). The insulin resistance-inducing properties of $\mathrm{PG}$ depend on rapid delivery (Kristensen and Raun, 2007). It is possible, therefore, that the cows in the present study had lower peak values of glucose and insulin because the supplements were fed instead of administer as a drench. Nevertheless, the actual purpose of this study was to investigate the effects of these supplements under practical conditions with an allocation method that does 
Table 3. Final mixed linear regression models of plasma concentrations of glucose, NEFA, and BHBA from 0 to 63 DIM in 672 dairy cows across 12 commercial Swedish herds supplemented with glycerol (GLY), propylene glycol (PG), or nothing (control, CON) in early lactation (2007-2009)

\begin{tabular}{|c|c|c|c|c|c|c|c|c|c|c|}
\hline \multirow[b]{2}{*}{ Variable } & \multirow[b]{2}{*}{ Class } & \multicolumn{3}{|c|}{ Glucose $(\mathrm{m} M)$} & \multicolumn{3}{|c|}{ Ln NEFA $(\mu \mathrm{Eq} / \mathrm{L})$} & \multicolumn{3}{|c|}{ Ln BHBA $(\mathrm{m} M)$} \\
\hline & & Est. ${ }^{1}$ & $P$-value & $95 \%$ CI & Est. & $P$-value & $95 \% \mathrm{CI}$ & Est. & $P$-value & $95 \% \mathrm{CI}$ \\
\hline Intercept & & 2.90 & $<0.0001$ & $2.76 ; 3.05$ & 5.92 & $<0.0001$ & $5.76 ; 6.09$ & -0.30 & $<0.0001$ & $-0.14 ; 0.45$ \\
\hline \multirow{2}{*}{ Treatment ${ }^{2}$} & GLY & -0.006 & 0.87 & $-0.07 ; 0.06$ & 0.05 & 0.22 & $-0.03 ; 0.13$ & 0.009 & 0.83 & $-0.06 ; 0.08$ \\
\hline & $\begin{array}{l}\mathrm{PG} \\
\mathrm{CON}\end{array}$ & 0.03 & $\begin{array}{l}0.37 \\
\text { Ref. }{ }^{3}\end{array}$ & $-0.04 ; 0.10$ & \multicolumn{3}{|c|}{ Ref. } & \multicolumn{3}{|c|}{ Ref. } \\
\hline \multirow[t]{2}{*}{ Breed $^{4}$} & SR & -0.16 & 0.005 & $-0.27 ; 0.05$ & 0.08 & 0.22 & $-0.05 ; 0.21$ & 0.12 & 0.05 & $0.002 ; 0.24$ \\
\hline & $\begin{array}{l}\text { SH } \\
\text { Other }\end{array}$ & 0.03 & $\begin{array}{l}0.63 \text { Ref. }\end{array}$ & $-0.08 ; 0.13$ & \multicolumn{3}{|c|}{ Ref. } & \multicolumn{3}{|c|}{ Ref. } \\
\hline Parity & $\begin{array}{l}1 \\
2\end{array}$ & $\begin{array}{l}0.42 \\
0.09\end{array}$ & $\begin{array}{c}<0.0001 \\
0.01\end{array}$ & $\begin{array}{l}0.35 ; 0.49 \\
0.02 ; 0.16\end{array}$ & $\begin{array}{l}-0.32 \\
-0.31\end{array}$ & $\begin{array}{l}<0.0001 \\
<0.0001\end{array}$ & $\begin{array}{l}-0.40 ;-0.23 \\
-0.39 ;-0.22\end{array}$ & $\begin{array}{l}-0.30 \\
-0.15\end{array}$ & $\begin{array}{l}<0.0001 \\
<0.0001\end{array}$ & $\begin{array}{l}-0.37 ;-0.23 \\
-0.22 ;-0.07\end{array}$ \\
\hline Calving season ${ }^{5}$ & $\begin{array}{l}\geq 3 \\
\text { Summer } \\
\text { Winter }\end{array}$ & 0.15 & $\begin{array}{c}\text { Ref. } \\
<0.0001 \\
\text { Ref }\end{array}$ & $0.09 ; 0.21$ & ${ }^{6}$ & Ref. & - & -0.07 & $\begin{array}{l}\text { Ref. } \\
0.03 \\
\text { Ref. }\end{array}$ & $-0.13 ;-0.008$ \\
\hline $\mathrm{DIM}^{7}$ & & 0.006 & $<0.0001$ & $0.004 ; 0.007$ & -0.02 & $<0.0001$ & $-0.02 ;-0.02$ & & & \\
\hline
\end{tabular}

${ }^{1}$ Est. = estimate

${ }^{2}$ Effect of treatment was forced into all models regardless of significance.

${ }^{3}$ Ref. $=$ reference.

${ }^{4} \mathrm{SR}=$ Swedish Red breed; $\mathrm{SH}=$ Swedish Holstein breed; Other $=$ crossbreed or other breed.

ᄃ $\quad{ }^{5}$ Summer $=$ cows calved between April 1 and September 30; winter = cows calving between October 1 and March 31.

득 $\quad{ }^{6}=$ effect was not significant $(P>0.05)$ and excluded from the model.

$\quad{ }^{7}$ DIM $=$ DIM when blood sampling occurred. 
Table 4. Final mixed linear regression models of plasma concentrations of insulin from 0 to 63 DIM and IGF-1 from 0 to 23 DIM in 672 dairy cows across 12 commercial Swedish herds supplemented with glycerol (GLY), propylene glycol (PG), or nothing (control; CON) in early lactation $(2007-2009)$

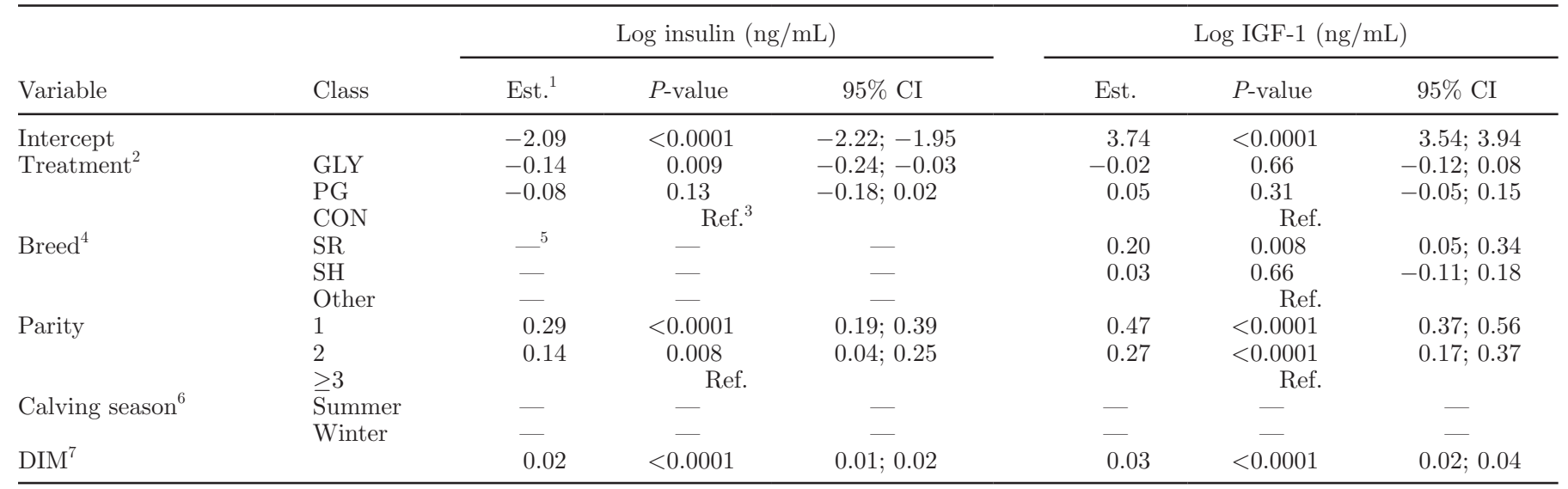

${ }^{1}$ Est. = estimate.

${ }^{2}$ Effect of treatment was forced into all models regardless of significance.

${ }^{3}$ Ref. $=$ reference.

${ }^{4} \mathrm{SR}=$ Swedish Red breed; $\mathrm{SH}=$ Swedish Holstein breed; Other $=$ crossbreed or other breed.

5

${ }^{6}$ Summer $=$ cows calved between April 1 and September 30; winter $=$ cows calving between October 1 and March 31.

${ }^{7} \mathrm{DIM}=$ DIM when blood sampling occurred.

not stress the animal and that is less labor intensive for the farmer to use.

In our study, the BHBA profile was surprisingly flat. It is unlikely, however, that the BHBA concentration on average did not change during the first 63 DIM. In general, BHBA concentrations are increased during the first $6 \mathrm{wk}$ pp (Ingvartsen et al., 2003) and it is therefore reasonable to believe that the BHBA curve would have looked different if samples had been taken more often during the early postpartum period. However, the sampling protocol in the present study (i.e., 3 samples per cow 3 wk apart) was focused on detection of long-term effects and was chosen as a compromise to allow the data to be further used in a study of the effect of GLY or PG on fertility.

As well as time of sampling in relation to calving and sampling interval, time of sampling in relation to administration of substances might affect the outcome. In our field study, cows were given the supplements during the morning and evening feedings. The samples were mainly taken during late morning, although some farms, for practical reasons, were visited during the afternoon. After drenching with $\mathrm{PG}$, an increase in insulin and glucose concentrations was seen after 90 min (Miyoshi et al., 2001; Butler et al., 2006; Rizos et al., 2008). It is likely that cows sampled at midday or in the afternoon had lower plasma concentrations of glucose and insulin than cows sampled at a morning visit, which might have affected the results of this study. However, cows from all treatment groups within one farm were sampled at the same time of day and therefore the bias due to differential misclassification would be reduced.

The doses of GLY and PG in this study were not glucogenically equivalent, although this was originally intended. In fact, cows given GLY received 20\% more glucogenic substance than cows given PG. To deal with this error, comparisons of the treatment effect were not made between GLY and PG, but between CON and GLY or PG, respectively.

Ingvartsen (2006) argued that the cows at risk of disease are those in physiological imbalance and that such cows may be identified based on plasma metabolites and hormones. Interestingly, in this study, herd explained only a small proportion of the variation in metabolites and hormone (generally $<19 \%$ ) whereas cows explained more than twice that explained by herd. One may speculate that cows in physiological imbalance (e.g., high concentrations of NEFA and BHBA and low concentrations of glucose) may respond differently to the treatments used in this study. It was not possible to analyze the data with regard to this because plasma samples were confounded by treatment.

In addition to metabolic parameters, disease incidence could be used to evaluate the severity of NEB. Of the 673 cows that fulfilled the period of supplemental feeding, 151 cows had any of the defined diseases at least once during the first 90 DIM. This corresponds 

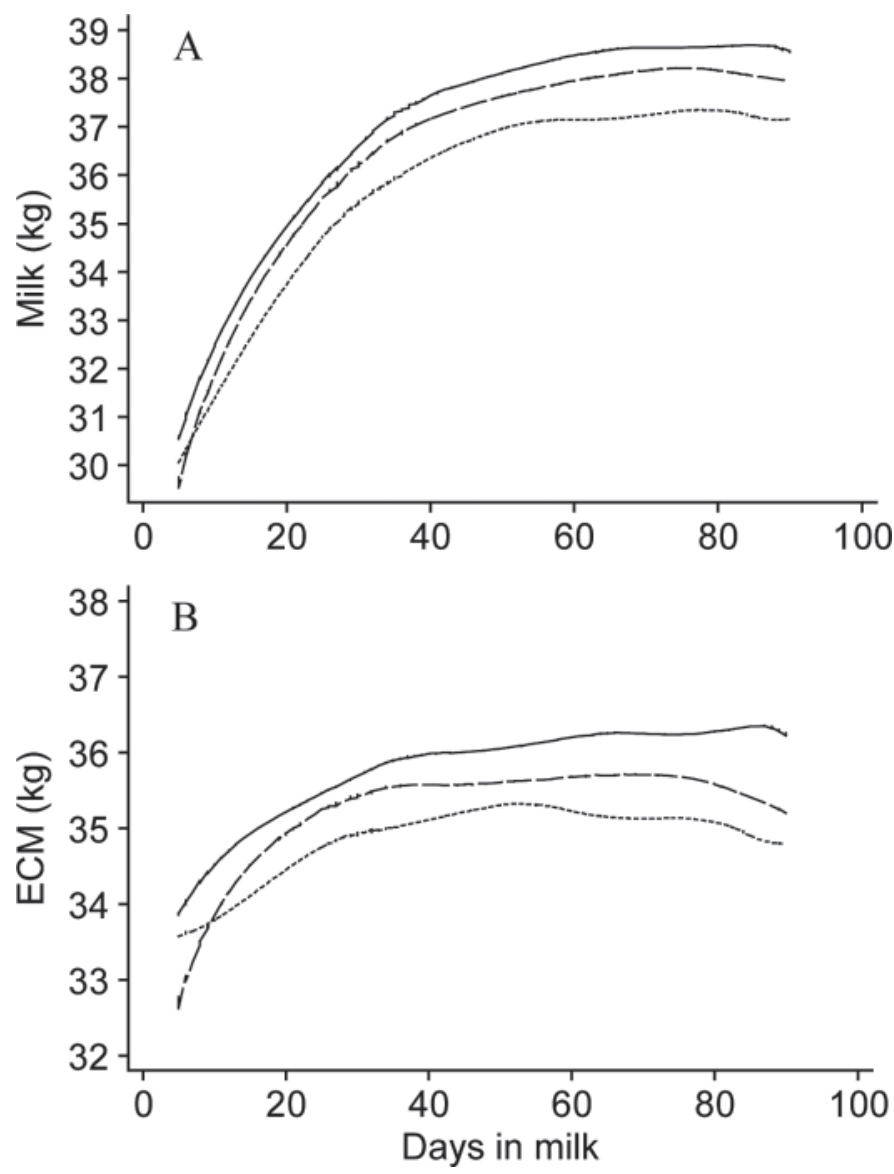

Figure 2. Predicted yields of (A) milk and (B) ECM across 673 dairy cows receiving supplemental feeding with glycerol (-), propylene glycol $(---)$, or control (...) from 0 to 21 DIM.

roughly to a disease incidence rate of 90 cases per 100 cow-years and is in accordance with recent data from 177 randomly selected Swedish dairy herds, in which the disease incidence rate of the same maladies was approximately 70 per 100 cow-years (Mörk et al., 2009). It would have been interesting to select herds with a high incidence rate of production diseases in order to evaluate the effect of the supplemental feeding in herds with potential severe NEB. However, this would have severely affected the willingness of the farmers to participate in the study and decreased the study population. Also, the aim of this study was to investigate the effect of these substances in average herds under normal conditions.

No differences in cases of veterinary-treated or farmer-recorded diseases were found in this study. However, this finding should be interpreted with caution because the study was not designed to investigate the effects of treatments on the occurrence of disease and the total number of disease cases was low. Detailed information about disease severity and duration was not available and veterinary treatment data could be under-reported, as indicated in a recent Swedish study (Mörk et al., 2009). Furthermore, the health data provide important background information and are presented for descriptive purposes.

Theoretically, cows provided glucogenic substances could use these to generate more milk, to improve their metabolic status, or both. In other words, it was expected that a cow's general level of production could influence the outcomes measured in this study. In the statistical models, it would therefore be advantageous to control for the amount of extra milk each cow potentially produced because of the GLY or PG treatment. In exploratory univariate analyses, the associations between milk yield and other explanatory variables, as well as the different outcomes, were investigated and found to be significant (results not shown). However, when multivariable regression was applied, milk yield was not found to be significant in any of the models except for the NEFA model. Because the causal relationship between milk yield and other variables in the analyses was unknown, we decided not to include milk yield as an explanatory variable in any of the final models.

In general, NEB starts before calving (Ingvartsen, 2006 ), indicating that it would be beneficial to start actions that aim to improve metabolic status even before calving. However, because of the field conditions of this study, it was impossible to start the supplemental feeding during the prepartum period.

This field study was randomized but not completely blinded. In other words, the control cows were known because they were not given any placebo. It is also possible that some of the farmers recognized PG by its typical unpleasant taste, compared with the sweet-tasting GLY. It can be expected that the extra attention given to the treated cows would strengthen the apparent positive effect of the supplement given. Nevertheless, such a difference was not demonstrated.

This study did not use any positive control and the study cannot therefore rule out that a glucogenic equivalent amount of barley or other grain would give the same effect on milk yield as GLY and PG. However, the field design of this study made an arrangement with a positive control less applicable.

Propylene glycol is considered unpalatable and generally does not stimulate feed intake (Nielsen and Ingvartsen, 2004), even if no effect on DMI is seen when PG was given as oral drench, mixed with concentrate, or mixed in TMR (Christensen et al., 1997). Glycerol, on the other hand, is sweet tasting, and barley with $10 \%$ glycerol was consumed willingly by heifers in a preference study (Spörndly and Åsberg, 2006). However, DeFrain et al. (2004) saw a decrease of DMI prepartum, 
Table 5. Final mixed linear regression models of milk yield measured as kilograms of milk and ECM from 673 dairy cows across 12 commercial Swedish herds supplemented with glycerol (GLY), propylene glycol (PG), or nothing (control; CON) in early lactation (2007-2009)

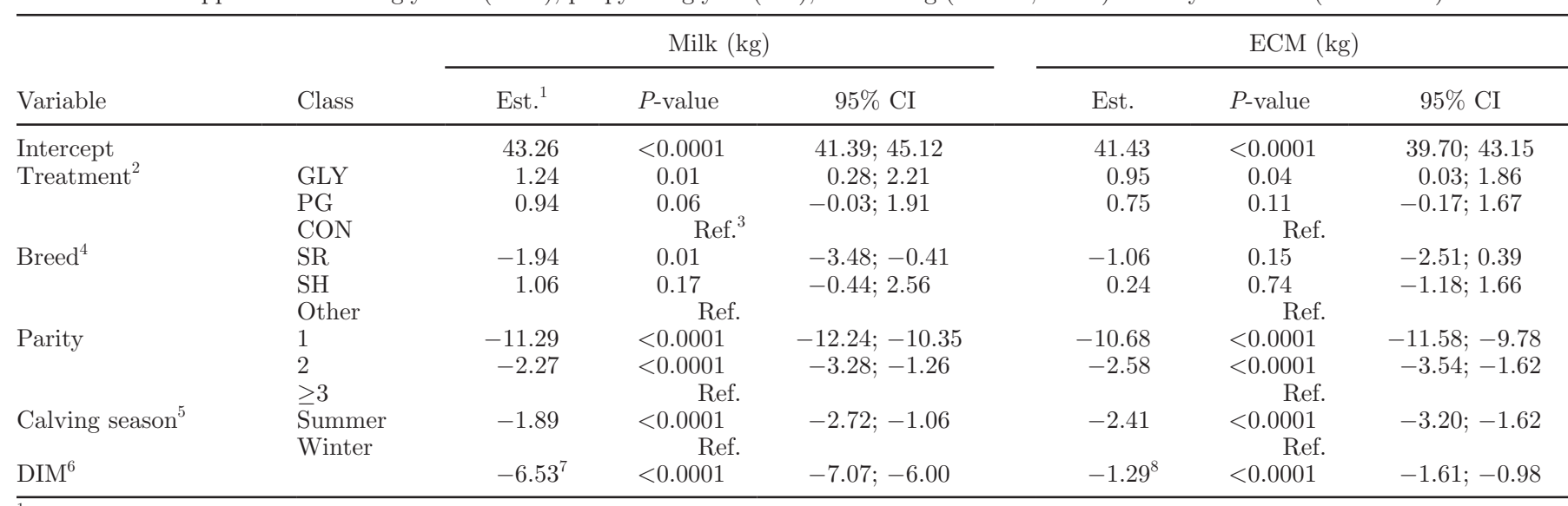

${ }^{1}$ Est. = estimate.

${ }^{2}$ Effect of treatment was forced into all models regardless of significance.

${ }^{3}$ Ref. $=$ reference.

${ }^{4} \mathrm{SR}=$ Swedish Red breed; $\mathrm{SH}=$ Swedish Holstein breed; Other $=$ crossbreed or other breed.

${ }^{5}$ Summer = cows calved between April 1 and September 30; winter = cows calving between October 1 and March 31.

${ }^{6} \mathrm{DIM}=\mathrm{DIM}$ of test milking.

${ }^{7} \mathrm{DIM}^{-1}$

${ }^{8} \mathrm{DIM}^{-2}$

but not postpartum, in cows fed glycerol top dressed in TMR starting $14 \mathrm{~d}$ before calving. In our study, it was not possible to monitor DMI. It should be noted that, although no apparent decrease of feed intake for any treatment group was reported by the farmers, an undetected decrease in DMI of PG-supplemented cows might have contributed to the lack of beneficial effects of PG.

Body weight of dairy cows is correlated with HG (Mäntysaari and Mäntysaari, 2008) and BCS (Roche et al., 2009). The present study did not show any differences in HG or BCS between any of the treatment groups. Formigoni et al. (1996) reported an unaffected

Table 6. Summary of proportion of variance in dependent variables explained at each level of the model hierarchy ${ }^{1}$

\begin{tabular}{lccc}
\hline & \multicolumn{3}{c}{ Source of variation } \\
\cline { 2 - 4 } Item & Farm & Cow & Residual \\
\hline Glucose $(\mathrm{m} M)$ & 0.17 & 0.33 & 0.49 \\
Ln $^{2}$ NEFA $(\mu \mathrm{Eq} / \mathrm{L})$ & 0.13 & 0.33 & 0.54 \\
Ln BHBA $(\mathrm{m} M)$ & 0.19 & 0.34 & 0.47 \\
Ln insulin $(\mathrm{ng} / \mathrm{mL})$ & 0.12 & 0.28 & 0.59 \\
Ln IGF-1 $(\mathrm{ng} / \mathrm{mL})$ & 0.16 & $\mathrm{NA}^{3}$ & 0.84 \\
BCS & 0.15 & 0.46 & 0.38 \\
Heart girth $(\mathrm{cm})$ & 0.10 & 0.64 & 0.26 \\
Milk $(\mathrm{kg})$ & 0.16 & 0.45 & 0.39 \\
ECM (kg) & 0.14 & 0.45 & 0.41 \\
\hline
\end{tabular}

${ }^{1}$ Results are derived from models presented in Tables 3,4 , and 5 .

${ }^{2}$ Natural logarithm.

${ }^{3}$ Not applicable.
BCS at d 50 after feeding PG daily before calving followed by drenching 4 times every third day. Propylene glycol fed as a top dress from $7 \mathrm{~d}$ prepartum until 45 DIM did not affect BW or body fat mobilization (Chibisa et al., 2008). Due to the high dose $(600 \mathrm{~mL} / \mathrm{d})$ used in the latter experiment, an effect might have been expected.

This field study of supplemental feeding with GLY or PG to dairy cows in early lactation indicates that plasma concentrations of certain hormones and metabolites were not increased. In contrast, plasma insulin concentration was decreased in cows fed GLY. Yields of milk and ECM during the first 3 mo of lactation increased by approximately $1 \mathrm{~kg}$ per cow and day in

Table 7. Cases of veterinary-treated or farmer-recorded diseases from 0 to $90 \mathrm{~d}$ in milk in a field study in which 673 Swedish dairy cows across 12 herds were fed supplements with glycerol (GLY; $\mathrm{n}=224$ ), propylene glycol $(\mathrm{PG} ; \mathrm{n}=222)$, and control $(\mathrm{CON} ; \mathrm{n}=227)$ in early lactation (2007-2009)

\begin{tabular}{lcrc}
\hline Disease & GLY & PG & CON \\
\hline Ketosis $^{1}$ & 5 & 4 & 8 \\
Mastitis $^{2}$ & 21 & 15 & 19 \\
Paresis $^{3}$ & 11 & 9 & 13 \\
Other $^{4}$ & 13 & 20 & 13 \\
Total & 50 & 48 & 53
\end{tabular}

${ }^{1}$ Ketosis, feed depression, or displacement of the abomasum.

${ }^{2}$ Acute mastitis or fever caused by other infectious disease.

${ }^{3}$ Puerperal paresis or hypomagnesemia.

${ }^{4}$ Other disease treated by a veterinarian or reported by the farmer. 
cows supplemented with GLY. Altogether, this might indicate that the metabolic status of cows supplemented with GLY was improved. Supplemental feeding with PG may increase milk yield by approximately $1 \mathrm{~kg} / \mathrm{d}$, but without the subsequent increase in ECM. Glycerol is a byproduct of biodiesel, and the cost of this substance, compared with PG, has decreased during the last decade. To give supplemental feeds seems to be less labor consuming compared with administering GLY or PG as an oral drench. The benefit of feeding GLY to increase milk yield needs to be investigated from an economic point of view. Studies investigating the effect of supplemental feeding of GLY and PG on fertility are also needed.

\section{CONCLUSIONS}

The results of this study indicate that supplementation with GLY during the first 3 wk in lactation could increase milk and ECM yield during the first 90 DIM without a subsequent decrease of metabolic status, measured as plasma levels of metabolites and hormones, BCS, and heart girth width. Our results further show that supplemental feeding with PG could increase milk yield without a subsequent decrease in metabolic status.

\section{ACKNOWLEDGMENTS}

This study was financially supported by the Swedish University of Agricultural Sciences (SLU) and Skaraborgs läns nötkreatursförsäkringsbolag (Skara, Sweden). The glycerol and propylene glycol used in this study were provided by Lantmännen Lantbruk (Malmö, Sweden). We thank Torben Larsen and staff at the laboratory at the Department of Animal Health and Biosciences, University of Aarhus (Foulum, Denmark) for efficient handling of samples. We also thank Anneli Axelsson and Gunilla Jakobsson (SLU, Skara, Sweden) for assisting in sampling and data management. Johan Lyhagen (Uppsala University, Uppsala, Sweden), Jan Hultgren (SLU, Skara, Sweden), Marie Mörk (SLU and Swedish Dairy Association, Uppsala, Sweden), and Ulf Emanuelson (SLU, Uppsala, Sweden) are acknowledged for discussions on statistical matters and Stefan Gunnarsson (SLU, Skara, Sweden) for comments on the manuscript. Finally, we are most grateful to the farmers participating in this study.

\section{REFERENCES}

Bodarski, R., T. Wertelecki, F. Bommer, and S. Gosiewski. 2005. The changes of metabolic status and lactation performance in dairy cows under feeding TMR with glycerin (glycerol) supplement at periparturient period. Electron. J. Polish Agric. Univ. 8:22-30.
Butler, S. T., S. H. Pelton, and W. R. Butler. 2006. Energy balance, metabolic status, and the first postpartum ovarian follicle wave in cows administered propylene glycol. J. Dairy Sci. 89:2938-2951.

Chibisa, G. E., G. N. Gozho, A. G. V. Kessel, A. A. Olkowski, and T. Mutsvangwa. 2008. Effects of peripartum propylene glycol supplementation on nitrogen metabolism, body composition, and gene expression for the major protein degradation pathways in skeletal muscle in dairy cows. J. Dairy Sci. 91:3512-3527.

Christensen, J. O., R. R. Grummer, F. E. Rasmussen, and S. J. Bertics. 1997. Effect of method of delivery of propylene glycol on plasma metabolites of feed-restricted cattle. J. Dairy Sci. 80:563-568.

Chung, Y. H., I. D. Girard, and G. A. Varga. 2009a. Effects of feeding dry propylene glycol to early postpartum Holstein dairy cows on production and blood parameters. Animal 3:1368-1377.

Chung, Y. H., C. M. Martinez, N. E. Brown, T. W. Cassidy, and G. A. Varga. 2009b. Ruminal and blood responses to propylene glycol during frequent feeding. J. Dairy Sci. 92:4555-4564.

DeFrain, J. M., A. R. Hippen, K. F. Kalscheur, and P. W. Jardon. 2004. Feeding glycerol to transition dairy cows: Effects on blood metabolites and lactation performance. J. Dairy Sci. 87:41954206.

Donkin, S., and P. Doane. 2007. Glycerol as a feed ingredient for dairy cows. Pages 97-103 in Proc. Tri-state Dairy Nutrition Conference, Fort Wayne, IN.

Drackley, J. K., H. M. Dann, G. N. Douglas, N. A. J. Guretzky, N. B. Litherland, J. P. Underwood, and J. J. Loor. 2005. Physiological and pathological adaptations in dairy cows that may increase susceptibility to periparturient diseases and disorders. Ital. J. Anim. Sci. 4:323-344.

Edmonson, A. J., I. J. Lean, L. D. Weaver, T. Farver, and G. Webster. 1989. A body condition scoring chart for Holstein dairy cows. J. Dairy Sci. 72:68-78.

Fisher, L. J., J. D. Erfle, G. A. Lodge, and F. D. Sauer. 1973. Effects of propylene glycol or glycerol supplementation of the diet of dairy cows on feed intake, milk yield and composition, and incidence of ketosis. Can. J. Anim. Sci. 53:289-296.

Formigoni, A., M.-C. Cornil, A. Prandi, A. Mordenti, A. Rossi, D. Portetelle, and R. Renaville. 1996. Effect of propylene glycol supplementation around parturition on milk yield, reproduction perfomrance and some hormonal changes and metabolic characteristics in dairy cows. J. Dairy Res. 63:11-24.

Friggens, N. C. 2003. Body lipid reserves and the reproductive cycle: Towards a better understanding. Livest. Prod. Sci. 83:219-236.

Goff, J. P., and R. L. Horst. 2001. Oral glycerol as an aid in the treatment of ketosis/fatty liver complex. J. Dairy Sci. 84(Suppl. 1):153. (Abstr.)

Harano, Y., M. Ohtsuki, M. Ida, H. Kojima, M. Harade, T. Okanishi, A. Kashiwagi, Y. Ochi, S. Uno, and Y. Shigeta. 1985. Direct automated assay method for serum or urine levels of ketone bodies. Clin. Chim. Acta 151:177-183.

Hoedemaker, M., D. Prange, H. Zerbe, J. Frank, A. Daxenberger, and H. H. D. Meyer. 2004. Peripartal propylene glycol supplementation and metabolism, animal health, fertility, and production in dairy cows. J. Dairy Sci. 87:2136-2145.

Ingvartsen, K. L. 2006. Feeding- and management-related diseases in the transition cow. Physiological adaptations around calving and strategies to reduce feeding-related diseases. Anim. Feed Sci. Technol. 126:175-213.

Ingvartsen, K. L., and J. B. Andersen. 2000. Integration of metabolism and intake regulation: A review focusing on periparturient animals. J. Dairy Sci. 83:1573-1597.

Ingvartsen, K. L., R. J. Dewhurst, and N. C. Friggens. 2003. On the relationship between lactational performance and health: Is it yield or metabolic imbalance that cause production diseases in dairy cattle? A position paper. Livest. Prod. Sci. 83:277-308.

Johnson, R. B. 1954. The treatment of ketosis with glycerol and propylene glycol. Cornell Vet. 44:6-21.

Juchem, S. O., F. A. P. Santos, H. Imaizumi, A. V. Pires, and E. C. Barnabe. 2004. Production and blood parameters of Holstein cows treated prepartum with sodium monensin or propylene glycol. J. Dairy Sci. 87:680-689. 
Kristensen, N. B., and B. M. L. Raun. 2007. Ruminal and intermediary metabolism of propylene glycol in lactating Holstein cows. J. Dairy Sci. 90:4707-4717.

LeBlanc, S. 2010. Monitoring metabolic health of dairy cattle in the transition period. J. Reprod. Dev. 56(Suppl.):S29-S35.

Linke, P. L., J. M. DeFrain, A. R. Hippen, and P. W. Jardon. 2004. Ruminal and plasma responses in dairy cows to drenching or feeding glycerol. J. Dairy Sci. 87(Suppl. 1):383. (Abstr.)

Liu, Q., C. Wang, W. Z. Yang, W. W. Zhang, X. M. Yang, D. C. He, K. H. Dong, and Y. X. Huang. 2009. Effects of feeding propylene glycol on dry matter intake, lactation performance, energy balance and blood metabolites in early lactation dairy cows. Animal 3:1420-1427.

Løvendahl, P., and H. M. Purup. 2002. Technical note: Time-resolved fluoro-immunometric assay for intact insulin in livestock species. J. Anim. Sci. 80:191-195.

Mäntysaari, P., and E. A. Mäntysaari. 2008. Relationship of body measurements and body condition score to body weight in modern Finnish Ayrshire cows. Acta Agric. Scand. A Anim. Sci. 58:170 178.

Miyoshi, S., J. L. Pate, and D. L. Palmqquist. 2001. Effects of propylene glycol drenching on energy balance, plasma glucose, plasma insulin, ovarian function and conception in dairy cows. Anim. Reprod. Sci. 68:29-43.

Mörk, M., A. Lindberg, S. Alenius, I. Vågsholm, and A. Egenvall 2009. Comparison between dairy cow disease incidence in data registered by farmers and in data from a disease-recording system based on veterinary reporting. Prev. Vet. Med. 88:298-307.

National Research Council. 2001. Nutrient Requirements of Dairy Cattle. 7th rev. ed. Natl. Acad. Sci., Washington, DC.

Nielsen, N. I., and K. L. Ingvartsen. 2004. Propylene glycol for dairy cows. A review of the metabolism of propylene glycol and its effects on physiological parameters, feed intake, milk production and risk of ketosis. Anim. Feed Sci. Technol. 115:191-213.

Olsson, S. O., P. Baekbo, S. Å. Hansson, H. Rautala, and O. Österås. 2001. Disease recording systems and herd health schemes for production diseases. Acta Vet. Scand. Suppl. 94:51-60.

Osman, M. A., P. S. Allen, N. A. Mehyar, G. Bobe, J. F. Coetzee, K. J. Koehler, and D. C. Beitz. 2008. Acute metabolic responses of postpartal dairy cows to subcutaneous glucagon injections, oral glycerol or both. J. Dairy Sci. 91:3311-3322.

Ospina, P. A., D. V. Nydam, T. Stokol, and T. R. Overton. 2010a Evaluation of nonesterified fatty acids and $\beta$-hydroxybutyrate in transition dairy cattle in the northeastern United States: Critical thresholds for prediction of clinical diseases. J. Dairy Sci. 93:546-554.

Ospina, P. A., D. V. Nydam, T. Stokol, and T. R. Overton 2010b. Associations of elevated nonesterified fatty acids and $\beta$-hydroxybutyrate concentrations with early lactation reproductive performance and milk production in transition dairy cattle in the northeastern United States. J. Dairy Sci. 93:1596-1603.

Rabe-Hesketh, S., and A. Skrondal. 2005. Multilevel and Longitudinal Modeling using Stata. 2nd ed. Stata Press, College Station, TX.

Rémond, B., E. Souday, and J. P. Jouany. 1993. In vitro and in vivo fermentation of glycerol by rumen microbes. Anim. Feed Sci. Technol. 41:121-132.

Rizos, D., D. A. Kenny, W. Griffin, K. M. Quinn, P. Duffy, F. J. Mulligan, J. F. Roche, M. P. Boland, and P. Lonergan. 2008. The effect of feeding propylene glycol to dairy cows during the early postpartum period on follicular dynamics and on metabolic parameters related to fertility. Theriogenology 69:688-699.

Roche, J. R., N. C. Friggens, J. K. Kay, M. W. Fisher, K. J. Stafford, and D. P. Berry. 2009. Invited review: Body condition score and its association with dairy cow productivity, health, and welfare. J. Dairy Sci. 92:5769-5801.

Spörndly, E., and T. Asberg. 2006. Eating rate and preference of different concentrate components for cattle. J. Dairy Sci. 89:21882199

Suriyasathaporn, W., C. Heuer, E. N. Noordhuizen-Stassen, and Y. H. Schukken. 2000. Hyperketonemia and the impairment of udder defense: A review. Vet. Res. 31:397-412.

Swedish Dairy Association. 2004. Handledning. Utdata för Kokontrollen, Stockholm, Sweden. (In Swedish)

Wang, C., Q. Liu, W. Z. Yang, W. J. Huo, K. H. Dong, Y. X. Huang, X. M. Yang, and D. C. He. 2009. Effects of glycerol on lactation performance, energy balance and metabolites in early lactation Holstein dairy cows. Anim. Feed Sci. Technol. 151:12-20. 